\title{
Organizational Trouble Shooting through Integration between the Theory of the Restrictions Thinking Process and Lean Tools
}

\author{
Tatiana Gondim do Amaral ${ }^{1}$ and Vitor Hugo Martins Resende ${ }^{2}$ \\ 1. Department of Post Graduate Degree Program in Geotechnical, Civil Construction and Structure (PPGECON), Federal \\ University of Goiás, Goiânia 74886044, Brazil \\ 2. Department of Engineering, Catholic University of Goiás, Goiânia 74605-220, Brazil
}

\begin{abstract}
The theory of constraints thinking process, created by Israeli physicist Eliyahu M. Goldratt, has emerged as a tool for achieving competitive advantage. Many researches also focused on the application of lean thinking developed by Toyota and proposed by Ohno. This philosophy has been proven to be effective in several production processes. This paper aims to propose a method of problem solving through the integration of theory of constraints thinking process and the principles of lean production. As a tool for problem identification, the method defends the use of current reality tree and, to solve problems, the lean thinking tools, proposed by Picchi. The developed method was implemented in a contractor. The research methodology was research-action. Among the results, there was a realistic diagnosis about the core problems in company. According to this, the core problem of the contractor is "the lack of commitment of manpower" that results in the main problem "the financial loss". The principle of perfection was verbalized as a proposal to solve the problems and the tools to be implemented for solving problems were "commitment of senior management to employees" and "simplicity in communication".
\end{abstract}

Key words: Commitment, people, culture, change, agreement, theory.

\section{Introduction}

The supply chain has two major flows: materials flow and information flow. In these flows, several factors contribute to the success or failure of companies that are inserted in or companies that are present in this chain.

For Bowersox et al. [1], the information flow is responsible for integrating the operation of the three major areas of the supply chain: customers, company and suppliers.

According to Christopher [2], information system is the mechanism by which the complex flows of materials, parts, subsets and finished products can be coordinated to get a service at a low cost.

Bowersox et al. [1] say that the primary objective of

Corresponding author: Tatiana Gondim do Amaral, Dr., research fields: management, lean construction and lean thinking. E-mail: tatiana_amaral@hotmail.com. managing the flow of information is to reconcile these differences in order to improve the performance of the chain.

Another point to be considered is the growth of demands in the construction area, which presses companies to identify and eliminate problems that prevent them from achieving their goals. This growth should continue in the coming years due to the 2014 World Cup and 2016 Olympics, and also because of the amount of financial support that wait for projects.

After three quarters of the year, the government still failed to accelerate the pace of investments planned for 2012. The total applied until September represented only $34 \%$ of the 90.2 million reais authorized by congress. The amount invested in the first nine months of this year (30.8 billion reais) is higher than the same period of previous year (28.8 billion reais), but this number is below the expenditure of 2010 (34.9 billion 
reais) in constant values [3].

When considering these prospects, companies increasingly need to analyze their flows and identify possible faults in the whole system to remain competitive and continue to make money.

According to Goldratt [4], the goal of every business is to make money, but for companies to succeed in achieving the established indicators and consequently achieve the goal, some management tools can be applied such as the Ishikawa diagram, PDCA (Plan, Do, Check and Act) methods, among others. Gupta and Boyd [5] claim that, along the years, the TOC (theory of constraints) has established itself as a good theory in the field of management. Klein and Drebuine [6], however, consider that the TOC has evolved into a philosophy that goes beyond the factory floor.

This paper proposes to use a new technique proposed by Goldratt [7] along with the principles of lean thinking.

This proposal aims innovation and reduction in the tools of the process of thinking by the constraints thinking process proposed by Goldratt [7] from five to two, including the use of lean production tool proposed by Picchi [8]. Allied to this simplifying advantage, the proposal is also innovative because it seeks to combine two techniques: one of key problem detection at the organization with other solution proposals of lean thinking, applied to the complex civil construction management field.

\section{Theory of the Restrictions Thinking Process}

In the 1980s, a new vision revolutionized the basics of business management: TOC, proposed by Goldratt and Cox [9].
According to Choe and Herman [10], the TOC evolved from a technique of scaling operations to a management philosophy focused on continuous improvement processes. In its early stage of development, the TOC main focus was the context of the production.

In the TOC, all efforts are focused on finding the constraint or bottleneck in production. Accordingly, we seek to analyze how to act so that the whole system works on the neck pace and increase the efficiency of the bottleneck. And, if the efficiency increases in a way that the process ceases to be the bottleneck, it is necessary to return to the beginning of the analysis process.

One of the Goldratt' statements [7] is that the whole system is governed by restrictions, which by definition are any obstacles that prevent the system from reaching its target, or rather the possible result can be called global optimum.

The impression is that the variables or system problems are many, but these problems are not independent [7]. According to the author, there is a strong connection of cause and effect between them.

The systems are therefore governed by these restrictions, however, due to the complexity of these systems, few problems will be able to influence globally, and only one or two problems can be the root cause of all other identified problems [7]. It is obvious that working in just one or two problems is less laborious and more efficient than acting on several.

According to Cox and Michael [11], the TOC seeks to answer three fundamental questions following: "What to change?”, “To what to change?” and "How to cause the change?". The tools to answer these questions are described in Table 1.

Table 1 Five tools of the thinking process [11].

\begin{tabular}{ll}
\hline Central question & Tool \\
\hline What to change? & CRT \\
To what to change? & EC (evaporating clouds) and FRT (future reality tree) \\
How to cause the change? & PRT (prerequisite tree) and TT (transition tree) \\
\hline
\end{tabular}




\section{The CRT (Current Reality Tree)) (What to Change?)}

The first stage of TOC thinking process is to answer "what to change" and, through verbalization, to build a effect-cause-effect relationship as a tree, called the CRT.

For Lacerda and Rodrigues [12], the connection of UEs (undesirable effects) should be built by arrows, as shown in Fig. 1.

After performed the UEs binding stage, we noticed that there are some UE which are not caused by any other UE. This UE is different from the others because of the impact that causes in the whole system and it is called root or central problem, as illustrated in Table 2 .

\section{Lean Production Principles}

The principles of lean production have been studied and applied in several kinds of companies. These principles are readings taken from the lean manufacturing philosophy, created by Ohno in the mid-20th century. The system also became known as the TPS (Toyota production system) because it has been applied in Toyota industry [13].

Picchi [8] conducted a survey on the lean thinking, where he analyzed concepts and thoughts of authors such as Womack et al. [14], Spear and Bowen [15] and Fujimoto [16]. From this work, Picchi [8] codified, in a tabular form (Table 3), the principles and examples of tools related to lean thinking.

\section{The Proposed Methodology (Which Lean Tool to Use?)}

The proposal is to integrate theory of constraints thinking process with the principles of lean production, using as a problem identification tool the current reality tree and to solve problem the lean thinking tools proposed by Picchi [8]. According to Table 4, the question to be verbalized after the application is: "Which lean tool to use?".

The proposal is, for each main problem found, a lean tool should be chosen to make the change and thus use all the effectiveness of lean to transform the reality.

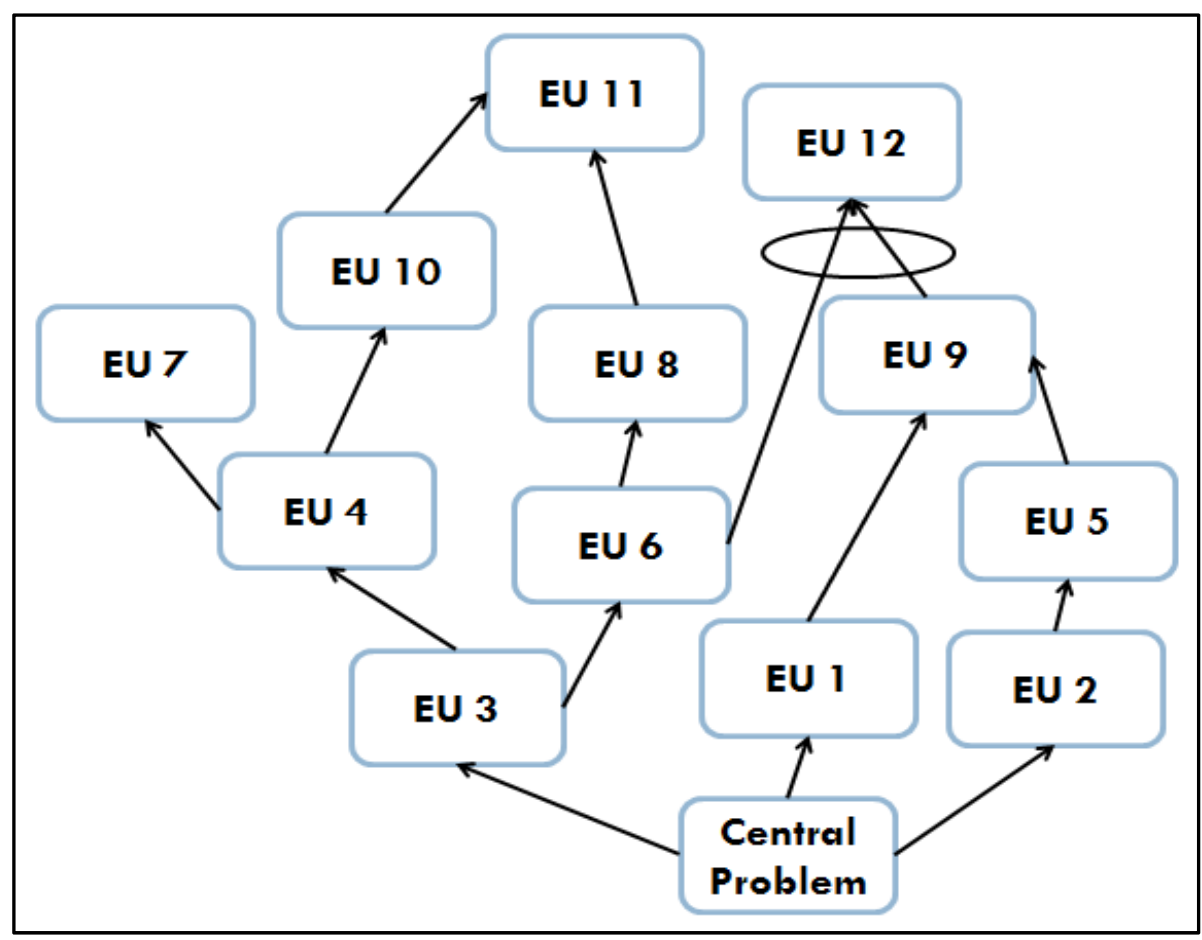

Fig. 1 CRT (current reality tree) [17]. 
Table 2 Consistency of current reality tree [12].

\begin{tabular}{|c|c|c|}
\hline Illustration & Consistency & Description \\
\hline 소 & Existence of entity & $\begin{array}{l}\text { Validate the actual existence of the entity (effect or cause), checking if } \\
\text { the cause and/or effect actually exist. }\end{array}$ \\
\hline & Existence of causality & $\begin{array}{l}\text { Consist the presence of the causal link between the effect and the cause, } \\
\text { using the statement IF } \Leftrightarrow \text { THEN. It should be checked if there is a direct } \\
\text { connection between the effect observed and the cause stated. }\end{array}$ \\
\hline & Tautology & $\begin{array}{l}\text { Avoid being redundant in the cause effect relation. } \\
\text { Tautology is actually a repetition of the effect; this is the cause and effect } \\
\text { and effect and cause. This type of situation should be avoided, because in } \\
\text { this way, the cause does not produce effect. }\end{array}$ \\
\hline & $\begin{array}{l}\text { Existence of predicted } \\
\text { effect (estimated) }\end{array}$ & $\begin{array}{l}\text { This can be done by using other end to establish that the cause does not } \\
\text { produce the effects observed or, to demonstrate that the cause produces } \\
\text { an effect that supports the original cause-effect relation. }\end{array}$ \\
\hline & $\begin{array}{l}\text { Sufficiency or } \\
\text { insufficiency of cause }\end{array}$ & $\begin{array}{l}\text { This consistency shows that for the existence of the undesirable effects, } \\
\text { it is necessary the combination of two causes. This demonstrates that } \\
\text { there is another cause to explain the observed effect. It is read as follows: } \\
\text { IF cause and cause THEN. }\end{array}$ \\
\hline Cause & Additional cause & $\begin{array}{l}\text { This type of relation demonstrates that any of the causes may result in the } \\
\text { occurrence of the undesirable effect. It may be more or less intense } \\
\text { depending on the combination of the causes. The table is read as follows: } \\
\text { IF cause OR cause THEN. }\end{array}$ \\
\hline & Clarification or clarity & $\begin{array}{l}\text { Clearly understand the cause-effect relation or the very existence of the } \\
\text { entity. If that is the case, formulate a further explanation of the cause } \\
\text { effect relation, of the relation or of the entity. }\end{array}$ \\
\hline
\end{tabular}

Table 3 Vision of the connections [8].

\begin{tabular}{ll}
\hline Principle & Tools examples \\
\hline Value & $\begin{array}{l}\text { Planned variety of products } \\
\text { Simultaneous engineering }\end{array}$ \\
\hline Value stream & Value stream maping, supplier partnerships \\
\hline \multirow{2}{*}{ Flow } & $\begin{array}{l}\text { Work cells, small batches, TPM (total productive maintenance) } \\
\text { Quality at the source; Poka-yoke (mistake proofing devices) } \\
\text { Operator balance chart, visual management }\end{array}$ \\
\hline Pull & $\begin{array}{l}\text { Take time (production rhythm), Kanban, production leveling } \\
\text { Rapid set-up, flexible equipment; Multi-functionality of operators }\end{array}$ \\
\hline \multirow{2}{*}{ Perfection } & $\begin{array}{l}\text { Self-managing teams; } 5 \text { whys, 5S program (seiri, seiton, seiso, seiketsu and shitsuke) } \\
\text { Company management commitment to employees, training everyone in the company and the suppliers in lean } \\
\text { principles and tools, simplicity in communication }\end{array}$ \\
\hline
\end{tabular}


Table 4 Central questions versus used tools.

\begin{tabular}{ll}
\hline Core questions & Tool \\
\hline What to change? & CRT \\
Which lean tool to use? & Lean tools proposed by Picchi [8] \\
\hline
\end{tabular}

\section{Methodology}

The methodology is classified as research-action. This choice is based on the goal of research-action: to promote the dissemination of knowledge, to promote the cycle of investigation/action and to integrate theory and practice.

According to Thiollente [18], this method fills the need for introduction to participatory methods in organizational environment, which enables a close cooperation relationship between researchers and members of the organization, required characteristics to this research.

Another determining factor in favor of this methodology is that the research-action and the reasoning process of the theory of constraints have as similarity the search for investigation and solution of complex problems through the integration of various individual views, and to generate innovating solutions. Thus, it supports Senge [19], who states that research-action leads the group to the exploration of complex issues in which the interaction between different visions elevates the understanding and generates original solutions.

The initial contact with the owner of the construction company was conducted via telephone and the first meeting has as purpose to clarify the technique and the principles of lean production. Two more meetings were scheduled for completion technique. The researchers conducted an interview at the end of the process in order to get the opinion about the proposed technique.

\section{Application of the Model: Case Study Contractor}

The company studied is located in Anápolisand, which was founded three years ago. Currently, it has a set of eight buildings, ranging from $80 \mathrm{~m}^{2}$ to $180 \mathrm{~m}^{2}$.

The model was applied and in the first step it was asked "what to change?"and five UEs were raised by the contractor, as illustrated in Fig. 2.

After the identification of UEs, the verbalization has begun to find the core problem and the logical tree was built according to Fig. 3 .

The first branch of the logical tree, connected by arrows, is constituted by these verbalized UEs: if there is a delay in the payment release by the government bank (UE1), then there is a need for a higher cash flow (UE2), if there is a need for a higher cash flow (UE2), then a larger amount of stopped money is needed (UE3), if a larger amount of stopped money is needed (UE3), then there is financial loss (UE4).

The second branch was verbalized: if there is delay or error in delivery of materials by some suppliers (UE5), then there is the need for anticipated purchase (UE6), if there is the need for anticipated purchase (UE6), then there is the need for maintaining higher inventory (UE7), if there is the need for maintaining higher inventory (UE7), then a larger amount of stopped money is needed (UE3), if there is a larger amount of stopped money is needed (UE3), then there is financial loss (UE4).

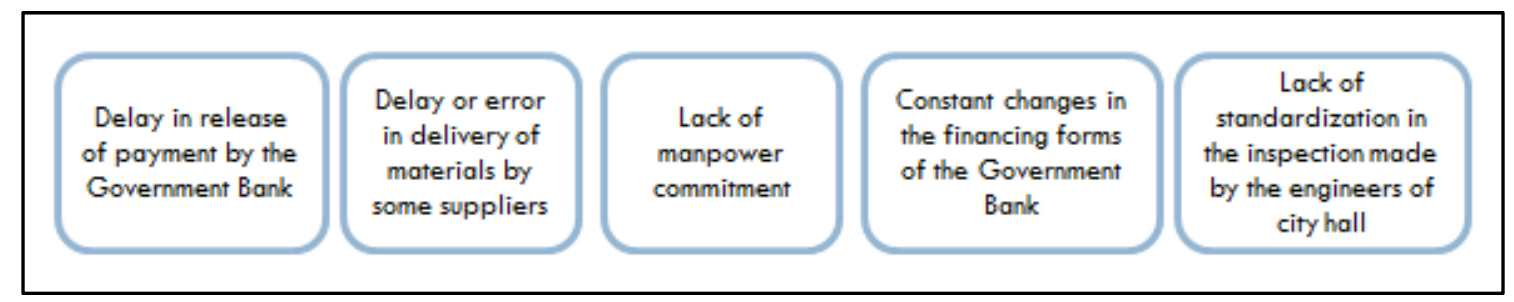

Fig. 2 Verbalization of five UEs in the contractor. 


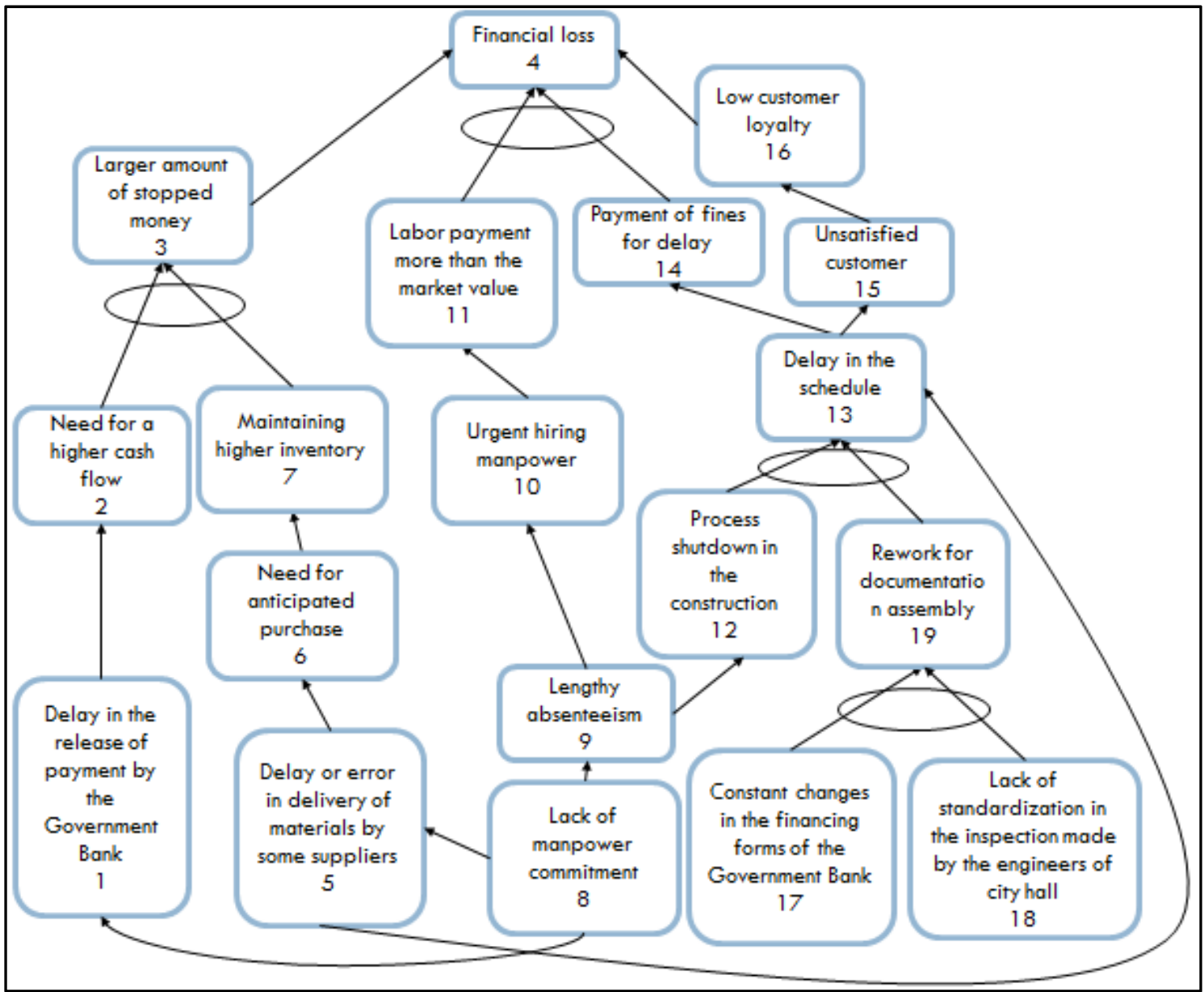

Fig. 3 CRT in the contractor.

Continuing in the second branch, it was verbalized: if there is delay or error in delivery of materials by some suppliers (UE5), then there is a delay in the schedule (UE13), if there is a delay in the schedule (UE13), then there is the payment of fine for delay (UE14), if there is a payment of fine for delay (UE14), then there is financial loss (UE4), or if there is delay or error in delivery of materials by some suppliers (UE5), then there is a delay in the schedule (UE13), if there is a delay in the schedule (UE13), then there is unsatisfied customers (UE15), if there is unsatisfied customer (UE15), then there is low customer loyalty (UE16), if there is low customer loyalty (UE16), then there is financial loss (UE4).

The third branch verbalized was: if there is a lack of manpower commitment (UE8), then there is lengthy absenteeism (UE9), if there is lengthy absenteeism
(UE9), then there is the need for urgent hiring manpower (UE10), if there is the need for urgent hiring manpower(UE10), then there is labor payment more than the market value (UE11), if there is labor payment more than the market value (UE11), then there is financial loss (UE4). Also in the third branch, it was verbalized: if there is lengthy absenteeism (UE9), then there is a process shutdown in the construction (UE12), if there is a process shutdown in the construction (UE12), then there is a delay in the schedule (UE13), if there is a delay in the schedule (UE13), then there is a payment of fine for delay (UE14), if there is a payment of fine for delay (UE14), then there is financial loss (UE4). Continuing in the third branch, it was verbalized: if there is a delay in the schedule (UE13), then there is unsatisfied customers (UE15), if there is unsatisfied customer (UE15), then there is low 
customer loyalty (UE16), if there is low customer loyalty (UE16), then there is financial loss (UE4). Finally in the third branch it was verbalized: if there is a lack of manpower commitment (UE8), then there is error or delay in delivery of materials by some suppliers (UE5), if there is delay or error in delivery of materials by some suppliers (UE5), then there is need for anticipated purchase (UE6), if there is need for anticipated purchase (UE6), then there is the need for maintaining higher inventory (UE7), if there is the need for maintaining higher inventory (UE7), then a larger amount of stopped money is needed (UE3), if a larger volume of stopped money is needed (UE3), then there is financial loss (UE4).

The last branch verbalized was: if there is constant change in the financing forms of the government bank (UE17) and if there is lack of standardization in the inspection made by engineers of city hall (UE18), then there is rework in the documentation assembly (UE19), if there is rework in the documentation assembly (UE19) then there is a delay in the schedule (UE13). From this moment, again we have two branches of verbalization: if there is a delay in the schedule (UE13), then there is a payment of fine for delay (UE14), if there is a payment of fine for delay (UE14), then there is financial loss (UE4). The other branch was: if there is a delay in the schedule (UE13), then there is unsatisfied customers (UE15), if there is unsatisfied customers (UE15), there is low customer loyalty (UE16), if there is low customer loyalty (UE16), then there is financial loss (UE4).

After finishing the construction of the CRT, it was questioned which would be the main UE and the consensus was the UE8 "Lack of manpower commitment".

After finding the core problem, it was verbalized the second question of the proposed model: Which lean tool to use?

In Table 3, through verbalization, the consensus was reached that the lean principle more appropriate was the principle of perfection, and the tool to be applied was simplicity in communication. According to this tool, the company must make clear to the employees the impacts the delay in the construction schedule can bring to the company, such as loss of new business and consequently the risk of losing jobs. And the company must communicate the suggested process improvements to employees who work at the government bank and at the city hall, and also inform them about the consequences of the delay in the construction.

After the application of the technique, a meeting was organized with the company's owner, who verbalized that: "In the beginning, it was difficult to understand the technique, but now I realized its effectiveness in solving problems".

\section{Conclusions}

The researchers found that, for the application of the proposed method, initially a review and understanding of the subject is required to enable the harmonization of concepts and procedures.

The application of the proposed method has low cost deployment, but it requires time availability of participants for reflection about causes and effects of the analyzed problems.

The method can achieve the proposed goal, which was to develop a method of solving business problems. According to this method, the current reality tree identifies the main problem and its consequences. And the lean thinking tools are actions, aligned with the discovered problem.

The authors applied the first step of the proposed methodology, the verbalization of the CRT with the question, "What to change?". In the contractor, the core problem was "lack of manpower commitment" and the main impact was "financial loss".

The second step, proposed by the method, was applied to the question "Which lean tool to use?". The tool chosen by the contractor was "simplicity in communication". The tools are classified by Picchi [8] on the principle of perfection. 
The tool was a consensus reached by the participants. The owner said that there is a high turn over because many employee do not understand clearly what are the salary and benefits paid by the company. Many workers leave the corporation for a little raise offered by other firm, wasting the chance of having a better position in the company.

Other tools are classified by Picchi [8], on the same principle they were verbalized but were not consensus as the best solution: self-managing teams, 5 whys, $5 \mathrm{~S}$ program, company management commitment to employees, training everyone in the company and the suppliers in lean principles and tools.

The researchers were also able to validate the method through meetings and to get the approval of the technique by the involved ones as a viable mechanism for identifying problems and solutions.

\section{References}

[1] D.J. Bowersox, D.J. Closs, M.B. Cooper, Supply Chain Logistic Management, McGraw-Hill, USA, 2002.

[2] M. Christopher, Logistics and Supply Chain Management, 4th ed., Great Britian, 2010.

[3] Sinduscon-SP, Union of Construction Industry of the State of São Paulo, The Output for Growth[Online], http://www.sindusconsp.com.br/msg2.asp?id=5785 (accessed Nov. 25, 2012).

[4] E.M. Goldratt, The Haystack Syndrome: Sifting Information out of the Data Ocean, Educator, São Paulo, 1991.

[5] M.C. Gupta, L.H. Boyd, Theory of constraints: A theory for operations management, International Journal of Operations \& Production Management (28) (10) (2008) 991-1012.

[6] D.J. Klein, M. Debruine, A thinking process for establishing management polices, Review of Business 16 (3) (1995) 31-37.

[7] E.M. Goldratt, It Is Not Luck, 3rd ed., The North River Press, Great Barrington, MA, EUA, 1994.

[8] F.A. Picchi, Opportunities application of lean thinking in construction, Built Environment Magazine, Porto Alegre 3 (1) (2003) 7-23.

[9] E.M. Goldratt, J. Cox, The Goal, 3rd ed., The North River Press, Great Barrington, MA, EUA, 2004.

[10] K. Choe, S. Herman, Using theory of constraints tools to manage organizational change: A case study of Eupripalabs, International Journal of Management and Organizational Behaviour 8 (6) (2000) 540-558.

[11] J. Cox, S. Michael, Handbook of Theory of Constraints, Porto Alegre, Bookman, 2002.

[12] D.P. Lacerda, L.H. Rodrigues, Understanding, learning and action: A thinking approach to the theory of constraints, process article, in: The Symposium for Excellence in Management and Technology, Resende, 2007.

[13] T. Ohno, Workplace Management, Productivty Press, New York, EUA, 1998.

[14] J.P. Womack, D.T. Jones, D. Ross, The Machine That Changed the World: Based on the Massachusetts Institute of Technology Study on the Future of the Automobile, 10th ed., Elsevier Press, 2004.

[15] S. Spear, H.K. Bowen, Decoding the DNA of Toyota production system, Harvard Business Review 77 (5) (1999) 96-106.

[16] T. Fujimoto, The Evolution of a Manufacturing System at Toyota, Oxford University Press, New York, 1999.

[17] C.M.T. Hilgert, Proposal of a method of decision making using the theory of constraints for production systems, Master Thesis, Federal University of Rio Grande do Sul, Porto Alegre, RS, Brasil, 2000.

[18] M. Thiollent, Methodology of Action Research, Cortez Press, São Paulo, 2000.

[19] P.M. Senge, The Fifth Discipline: The Art and Practice of the Learning Organization, Best Seller Press, São Paulo, 2000. 